\title{
ENGRAXAR NA PRAÇA: UM ESTUDO ETNOGRÁFICO SOBRE O AGENCIAMENTO DA MEMÓRIA COLETIVA DIANTE DA REMODELAÇÃO DO ESPAÇO PÚBLICO NO CENTRO DE PORTO ALEGRE.
}

\author{
Rafael Martins Lopo
}

Ana Luiza Carvalho da Rocha (Orientação)

Como pensar uma cidade do tamanho de Porto Alegre diante de um projeto de revitalização? A idéia de que as transformações acontecem constantemente, diariamente, derruba qualquer hipótese que pense que as mudanças que afetam a cidade são apenas aquelas feitas por projetos grandiosos de revitalização, legitimados pelo progresso e bemestar social. A cidade é grande, mas as transformações são tão particulares que é impossível condicionar a cidade inteira à uma lógica simples de revitalização. Este perigo é apontado por Henri-Pierre Jeudy(1945), indicando um esvaziamento e uma re-apropriação vaga dos conceitos de memória coletiva, patrimônio e identidade cultural. Ao limitar o patrimônio à padrões históricos e estéticos, acaba-se definido uma lógica da memória que não a da resignificação e da lembrança, repleta de conflitos e esquecimentos, que segundo o autor, estão materialmente ligados à ruínas e objetos ${ }^{1}$.

A etnografia aqui apresentada surgiu de pesquisas de campo realizadas na Praça da Alfândega, no centro de Porto Alegre, em um período delicado para seus freqüentadores e profissionais que ali estavam. A idéia inicial era tentar interpretar os jogos de memória de diferentes atores do lugar diante do processo de revitalização proposto pela prefeitura. Logo, vi que seria um empreendimento que me exigiria um dispêndio maior de tempo, e resolvi me concentrar em um "grupo" muito particular e "antigo"2 da Praça, os engraxates.

"Ali ó, onde tem a Multisom, era o Guiloço, um restaurante fino. Inclusive, inclusive, um ex-prefeito de Porto Alegre, muito meu amigo, começou como ajudante de cozinha no Guiloço”

Essa é apenas uma de muitas lembranças que seu João Estevão, um dos engraxates mais velho da Praça, tem de uma Porto Alegre que há muito não é a mesma.

\footnotetext{
${ }^{1}$ A "estética do abandono" também é apontada pelo autor, mas o processo em voga no centro surge de uma idéia arqueológica e museológica de revitalização a partir de grandes símbolos e prédios.

2 A imagem de "engraxates do centro", enquanto um grupo descaracterizado individualmente, é consideravelmente antigo e consagrado na memória dos porto-alegrenses, mas somente três ou quatro destes profissionais estão ali há mais de quatro décadas; por isso o uso de aspas.
} 
Os engraxates são dos grupos de trabalhadores que atuam na atual Praça da Alfândega, um dos mais antigos, atuando no local há aproximadamente cinco décadas. Segundo eles contam, e alguns livros sobre a história de Porto Alegre mencionam, os engraxates era um grupo que, nos anos 50, tinha, na "rua da Ladeira", atual General Câmara, seu ponto maior de concentração, devido à presença do Fórum e dos muitos escritórios de advocacia nas regiões vizinhas. Segundo me relatou Sr. Estevão, em um dos momentos de meu trabalho de campo no local:

\footnotetext{
"É.., ali na Ladeira tinha muito engraxate, alias, naquela época todo mundo era engraxate, só eu mais uns poucos resistimos. Tinha na Ladeira, se eu não me engano, na esquina com a Andradas, uma tabacaria, a Tabacaria Garcia, e em cima, na parte de cima, era o Taco de Ouro, onde tinha umas mesas de sinuca pro pessoal jogar"
}

Segundo alguns engraxates, foi quando as tabacarias começaram a desaparecer que todos começaram a procurar novos espaços e a Praça da Alfândega foi um dos locais escolhidos. Possivelmente por causa da efervescência masculina nas sociabilidades do local, como os cafés. Os cafés do centro, no começo até o meio do século, se fixaram como espaço de sociabilidade extremamente masculina, lugares onde o privado invadia o público, constituindo ambiências e sociabilidades que atuavam como palco de uma moda européia para a burguesia de Porto Alegre, segunda Sandra Pesavento.

Não só o espaço da alta classe, mas, como salienta Áries(1989), Perrot e outros, estes espaços são também formados por boêmios e "dândis", indivíduos estes que adotariam uma forma de vida anti-burguesa, mas sempre preocupada como o bem-vestir, com a distinção separada de regras sociais. O "dândi", "ator do teatro urbano", é segundo Baudelaire, aquele mais rico que os boêmios, não tão abastado como os burgueses e "que nunca passa menos de duas horas por dia se arrumando". Seja "dândi”, boêmio, burguês, intelectual, jornalista ou letrado, o homem porto-alegrense da primeira metade do século freqüentava espaços como os cafés, lugares de discussões políticas e culturais, altamente masculinizado. O footing, andar pelas ruas, estar com as roupas e os sapatos engraxados, fazia parte da paisagem do centro, e principalmente das áreas mais povoadas por outros homens. 
Interessante aqui seria ressaltar Richard Sennet (1997), que situa esta sociabilidade em um individualismo urbano que faz emergir novas formas materiais de conforto e sociabilidade. Segundo o autor, a exigência capitalista de trabalho na cidade que cresce constantemente criou lugares em que a busca pelo conforto tornou-se essencial. O café é um destes lugares, e acabou acompanhando uma lógica da cidade, de separação e distinção pelos espaços e uma individualização constante. Certamente, acompanhado o crescimento da cidade e a criação de grandes avenidas, o espaço externo dos cafés se tornou lugar de conversa, "mexerico", e sociabilidade mais ativa, enquanto o interior dos mesmos era freqüentado por pessoas de classe superior, que desejavam ficar sozinhas.

No Brasil, a lógica foi parecida. José Ramos Tinhorão(2005), explica que os "cafés-cantantes" tentaram refletir uma exaltação francesa de distinção dos "cafésconcerto", a sociabilidade destes espaços era, no começo, tomada de políticos, artistas e intelectuais, e aos poucos foi sendo dominada pelo som popular e conversas de rua.

Em Porto Alegre, segundo alguns dos engraxates, os encontros no centro eram constantes, e a presença de espaços como os cafés e os cinemas contribuíram para a escolha de um lugar para trabalhar.

Assim, a Praça sempre se situou como um lugar consagrado na memória dos passantes e habitantes da cidade, e já foi alvo de muitas remodelações e modificações em seu espaço, sempre atraindo a atenção das municipalidades para os aspectos da limpeza urbana. A Folha da Tarde de 1979, ressaltando a urgência por modificações.

\footnotetext{
"O certo é que a Praça, há muito tempo, estava necessitando de uma reforma em regra, não se justificando, de forma alguma, que permanecesse nas condições precárias em que vinha sendo mantida”(FOLHA DA TARDE, 17/01/79, pág.4)
}

O nome é um dos exemplos destas muitas modificações. A praça, primeiramente chamada de Praça da Quitanda, por ter muitos comerciantes e quitandeiros em volta do cais, teve, a partir de 1820, a presença do prédio da Alfândega, que removeu os quitandeiros para a Praça XV, chamada na época de Praça Paraíso. Isso fez com que seu nome mudasse para Praça da Alfândega. Antes disso, em 1883, a Praça teve seu nome mudado para Praça Senador Florêncio. Em 1912, com a construção do Cais do Porto, o governo teve que aterrar uma faixa de 100 metros de largura, da frente da Praça ao portão 
principal do Porto, onde foram erguidos dois prédios: a delegacia Fiscal do Tesouro Nacional, atual MARGS, e o prédio dos Correios e Telégrafos, atual Memorial do Rio Grande do Sul. À frente desses dois prédios foi estabelecida uma pequena praça, chamada de Praça do Barão de Rio Branco. Junto com os prédios, há de se pensar mais uma vez naqueles que passam; marca-se na Praça o espaço dos funcionários dos bancos e dos correios, que precisam e usam sapatos, necessitam de cuidado muito grande com a aparência de seus calçados.

Mas uma das principais mudanças na modelação da Praça foi em 1979, quando um projeto uniu as duas Praças, abraçando a Rua Sete e Setembro. Uma tal transformação fez com que a Praça perdesse a rua que a demarcava pelo Oeste após a construção do prédio da Caixa Econômica Federal, e tendo o seu nome mudado de novo para Praça da Alfândega, pois o povo continuava a chamá-la assim. A demarcação das ruas é outro fator importante a ser pensado. Gilberto Freyre indagava-se sobre a representação do estar na calçada demarcada, por puro prazer, ou estar trabalhando, na rua, sem asfalto. Para Gilberto Freyre, a utilização do sapato pelo mais rico, certamente demarcava muito bem as fronteiras entre as classes. Ter os pés finos, bonitos e bem cuidados era necessário para um bom homem, sendo possível isto somente com a utilização de sapatos resistentes, que permitiam longas caminhadas, e só eram fabricados fora do Brasil. O escravo, ou até mesmo liberto, utilizando-se da força e da rua, com os pés na lama e na sujeira, não tinha seus pés protegidos pelas botinhas portuguesas ou sapatos ingleses com sola de borracha.

Foi ainda no ano de 1979, que os engraxates receberam novas cadeiras, presas nas árvores, e sem proteção, fato que é recorrente na fala da maioria dos engraxates com quem conversei:

\footnotetext{
"Elas não tinha cobertura, não tinha essa cobertura, era só uma cadeira e um guarda-sol, e o latão era assim(mostrando que erafechado em baixo), $e$ nós podia guardar o material dentro se quisesse, mas como nós sabia que tinha os vândalo iam arromba, a gente não guardava, só guardava ali o Guarda-Sol, coisa simples, guardava aqui nesse prédio aí(apontando para o prédio atrás dele), guardava no antigo Grande-Hotel, quando queimou, tinha um zelador lá, e outros guardavam em outro lugar. Aqui onde queimou na esquina da João Manuel com a Sete de Setembro, uns cabarézinho ali que tinha... ai , me esqueço o nome agora;" ( Seu Armando, engraxate há mais e quarenta anos na Praça)
} 
Segundo Halbwachs(1990), há uma relação muito intrínseca entre a memória coletiva e os espaços em que ela se enraíza, uma vez que esta memória se constitui e se constrói, a todo o momento, em uma relação intrínseca com os bens materiais e simbólicos de uma determinada sociedade. O conceito de memória social apoiado em Halbwachs vai contra o pensamento bergsoniano ${ }^{3}$ que afirmava que a memória é uma maneira de reativar lembranças perdidas no inconsciente, e tende sempre a se repetir da forma mais fiel possível. A memória, para Halbwachs, não se constitui sempre na mesma imagem, porque não somos os mesmos, e estamos com outros juízos, imbuídos de outros valores. Quando lembramos de algum fato, estamos lembrando apenas daquilo em que prestamos a atenção, aquilo que nosso grupo, ou seja o "quadro social” a qual pertencíamos, nos fazia perceber, nos fazia selecionar alguns elementos que eram importantes para nós e para aquele contexto. Seria uma seleção de imagens necessárias e importantes, que somente nós, preocupados com coisas nossas, estaríamos atentos.

Seguindo o pensamento de ECKERT E ROCHA(2000), contemplar a memória significa reconhecer a força intangível das motivações simbólicas que regem as ações humanas, o que significa que não se pode ignorar o espaço de figurações de utopias coletivas diferenciadas. Por mais, a memória não se configura apenas em um tradicionalismo nostálgico e sentimental, mas nos mitos, saberes, fazeres e tradições que são perenizados, primeiramente, no interior de manifestações culturais humanas.

O sapato bem engraxado, os passeios nas calçadas, as conversas dos políticos nos cafés, o desfile nas entradas dos cinemas e das casas lotéricas, o traje impecável das pessoas que freqüentavam estes lugares, todas estas pequenas transformações da Praça são todas importantes para se compreender o lugar dos engraxates na memória coletiva deste espaço:

"Bem, ali na Ladeira eu nunca trabalhei, comecei e to até hoje aqui na Praça. Ali no Grande Hotel, ali tinha muita gente importante que fazia fila pra engraxar comigo. Sabe aquele prefeito que foi cassado? $O$ Cereno Chele, ele engraxava comigo, ele e um monte de jornalista importante" (Seu Estevão)

\footnotetext{
$\overline{{ }^{3} \text { Ver as considerações de BOSI(1994) }}$
} 
Não somente a relação política, mas a política de relações e sociabilidades evidenciadas pelos trajes é importante para pensar a escolha do lugar pelos engraxates e também esta relação do espaço com a memória. Salientando a idéia de Gabriela Hasimoto Aguieiros(1999), percebemos a importância do traje no decoro e na relação social na metrópole. O traje é colocado aqui como um dos símbolos de prestígio e sabedoria social é preciso saber a roupa certa a ser usada no lugar certo.

Ainda mais abrangente, porém mais valiosa para tal interpretação, a teoria de Gilberto Velho(1994) coloca-nos diante de visões e constituições de significados através da interação entre indivíduos e da interiorização de códigos externos que apontam para estilos de vida negociados na metrópole.

O processo maior que engloba as diferentes formas dos indivíduos de viver e lidar com a questão da individualidade na sociedade contemporânea é chamado pelo autor de "Construção Social da Realidade". Segundo Gilberto Velho, há sempre algum tipo de classificação e distinção do indivíduo pelo pertencimento à um grupo, religião, etnia, e essas categorias de classificação podem ser tomadas como autenticas ou desviantes.

Sobre a mobilidade do indivíduo, o autor fala que o agente empírico desempenha papéis que lhe permitirão elaborar uma identidade particular e única de acordo com o espaço que lhe é conferido.

E para tentar captar os pequenos fragmentos de uma memória coletiva do lugar, nas falas e no cotidiano dos engraxates face aos atuais projetos de revitalização da Praça da Alfândega, o método etnográfico acoplado à observação participante no local aparece como a melhor ferramenta para esta pesquisa.

A observação participante, as conversas e entrevistas não-diretivas, assim como as tensões pessoais que tive como aprendiz de antropólogo em campo, me permitiram, e ainda me permitem, até hoje, a perceber os pequenos jogos da memória a que acham-se submetidos os engraxates na relação que tecem entre o seu ofício e o espaço da Praça da Alfândega. Um das maiores tensões vivida por mim em campo foi a alteração de minha aproximação com os engraxates de cliente para pesquisador, tanto entre aqueles que se situam mais próximos à General Câmara, quanto aos que localizam-se na Rua Capitão Montanha. Ao ser identificado como pesquisador, recebo o convite imediato de Seu Estevão para conhecer sua casa e as fotos antigas da Praça que ele tinha guardadas, ainda 
que a posição de cliente tenha conseguido me aproximar deste grupo social e entender um pouco mais de seu oficio:

\footnotetext{
"Tu entende de graxa? - me pergunta Seu Armando. Não me diz que tu engraxa em casa com aquelas NUGGET!! Aquilo só acaba com o sapato, tem engraxar com as pomada mesmo, com essas latinhas redondas, que tu compra no super mesmo"
}

Antes de me aprofundar na pesquisa, fazia trabalhos de campo na condição de cliente. Chegava no local, engraxava, puxava um assunto, e me sentia seguro com relação a isso. Porém, o trabalho antropológico exige mais de um pesquisador. Como salienta ECKERT e ROCHA(2000a), o trabalho na cidade anseia e força à uma ruptura que não é só típica da Antropologia em si, mas da pesquisa antropológica na cidade e sobre a cidade. Ao me colocar na condição de pesquisador deste espaço, é eminente que as experiências pessoais e subjetivas da minha relação com este universo estejam a todo momento exigindo uma reflexão. A interioridade exige ao mesmo tempo uma reflexão acerca do próprio fazer antropológico, guiado pelas próprias experiências pessoais, e uma própria reflexão antropológica sobre como reconhecer a diferença de um outro que se espelha na figura do pesquisador pela experiência citadina, de compartilhar talvez os mesmos espaços e lugares afetivos.

Outro importante aspecto tem sido o que o trabalho de campo tem me permitido acompanhar as constantes mudanças na Praça da Alfândega ligadas aos preparativos para a Feira do Livro prestes a ser montada, e com isto perceber a inviabilidade das pequenas remodelações cotidianas que fazem parte deste lugar e as reações de seus "habitués”. Estas pequenas remodelações diárias acumuladas no tempo configuram a duração e ambiência desta praça na memória coletiva dos porto-alegrenses, permitindo aqueles que nela habitam ordenar, através de atos de rememoração, seu lento processo de transformação e onde a arte de narrar faz de cada engraxate um artesão de sua própria memória e duração.

Isto porque, seguindo EKCERT et ROCHA(1999), a Praça da Alfândega é um destes lugares da cidade de Porto Alegre que se pode considerar como ponto de inserção de vários mundos, totalizando, no plano do espaço fantástico da memória coletiva, diferentes estilos de vida e visões de mundo daqueles que por ali deixaram suas pegadas, e que são 
“chamados constantemente a resistir ao tempo do desgaste e do desaparecimento de seus referentes materiais".

Em outro artigo, ROCHA(1996) retoma a cidade como fabricante e possuidora de utopias, guardiã de bens intangíveis da Tradição Ocidental, lugar onde se encerra toda crença no individualismo democrático. Ao se falar na preservação de bens intangíveis, como a memória de Porto Alegre na Praça da Alfândega, estamos falando de toda uma comunidade de símbolos, uma dinâmica de sentidos, e por isso, ao colocar estas em um conjunto de leis e regras, estamos inferindo também em formas de ser e viver que nãodiscursivas de grupos sociais, criando impasses.

Primeiro, porque a idéia científica de bens culturais não abriga estas formas nãodiscursivas de ser e viver, e torna-se necessário ampliar este conceito, para que as "formas do espírito humano que se manifestam nas ações do mundo" possam ser entendidas pela nossa cientificidade. Segundo, é preciso estar atento ao fato de que os bens culturais não se encerram em simples enunciados, como nos decretos de tombamento e políticas culturais, sendo modificados constantemente. Terceiro, porque tentar traduzir estas formas culturais em textos científicos pode significar um congelamento do dinâmico processo de produção destes bens.

Neste sentido, contemplar a memória no corpo de uma política patrimonial significa reconhecer a força intocável e "invisível” das motivações simbólicas que regem as ações humanas nestes territórios. O desafio da pesquisa foi de interpretar as alterações sofridas pela Praça da Alfândega do ponto de vista da sua dimensão de complexidade, espaço que se configura a partir de diferentes teias de significados ${ }^{4}$, na expressão de Geertz (1989). Preservar e valorizar bens culturais e patrimoniais só tem sentido se pensarmos tais bens no corpo de memórias coletivas e negociadas e não a concebermos "como mero território de reativação de tradições perdidas e nostalgia do passado".

\section{REFERENCIAS}

AGUIEIROS, Gabriela Hasimoto. "O Traje e o Decoro", in Vergonha e Decoro na Vida Cotidiana da Metrópole / org. José de Souza Martins. São Paulo: Hucitec, 1999.

ARIES, Philippe et al. História da vida privada. São Paulo: Companhia das Letras, $1989,5 \mathrm{v}$.

BOSI, Ecléa. Memória e Sociedade: lembranças de velhos. São Paulo: Companhia das Letras, 1994.

\footnotetext{
${ }^{4}$ Expressões de Geertz utilizadas por Gilberto Velho
} 
ECKERT, Cornelia; ROCHA, Ana Luiza Carvalho da. "Premissas para o estudo da memória coletiva no mundo urbano contemporâneo sob a ótica dos itinerários de grupos urbanos e suas formas de sociabilidade". In: Revista Margem. Puc, SP, 1999 p. 243 a 259.

ECKERT, Cornelia; ROCHA, Ana Luiza Carvalho da. . A memória como espaço fantástico, in Iluminuras, Série do Banco de Imagens e Efeitos Visuais, número 2. Porto Alegre: BIEV, PPGAS/UFRGS, 2000.

ECKERT, Cornelia; ROCHA, Ana Luiza Carvalho da. A interioridade da experiência temporal do antropólogo como condição da produção etnográfica, in Iluminuras, série do Banco de Imagens e Efeitos Visuais, número 13. Porto Alegre: BIEV, PPGAS/UFRGS, 2000a.

FRANCO, Sérgio da Costa. Guia histórico de Porto Alegre. Porto Alegre: Ed, da Universidade/UFRGS, 1988.

GEERTZ, Clifford. A Interpretação das Culturas. Rio de Janeiro: LTC, 1989. HALBWACHS, Maurice. Memória coletiva. São Paulo: Vértice,990.

JEUDY, Henri-Pierre. Memórias do Social. Rio de Janeiro: Forense Universitária, 1990. ROCHA, Ana Luiza Carvalho da. Cidade como lugar do próprio e do absoluto: os dilemas de uma política de valorização de bens culturais in Seminário Preservação e valorização de bens culturais intangíveis. Prefeitura de Porto Alegre: Secretaria Municipal de Cultura, 1996.

SENNET, Richard. O corpo e a cidade na civilização ocidental. Rio de Janeiro: Record, 1997.

TINHORÃO, José Ramos. Os sons que vêm da rua. São Paulo: Ed. 34, 2005.

VELHO, Gilberto. Projeto e metamorfose. Antropologia das sociedades complexas. RJ: Jorge Zahar, 1994. 